\title{
Recent Advances in Diagnosis and Severity Assessment of Acute Pancreatitis
}

\author{
Jayanta Paul \\ Department of Gastroenterology, Desun Hospital and Heart Institute, \\ Kolkata, India \\ Received November 9, 2019; Accepted May 28, 2020.
}

Key words: Acute pancreatitis - Diagnostic criteria - Diagnostic algorithm Classification - Severity assessment - Recent advances - Scoring system

Abstract: The incidence and prevalence of acute pancreatitis (AP) is increasing over time. The diagnosis of acute pancreatitis is established by revised Atlanta criteria (2012). Multiple criteria and scoring systems have been used for assessment of severity of AP. Majority of acute pancreatitis cases (80\%) are mild, the challenge remains in early diagnosis, severity assessment and treatment of severe AP and its complications. Assessment of severity of AP is important part of management because line of treatment depends on aetiology and severity of acute pancreatitis. In this article a comprehensive review of recent advances in diagnosis and severity assessment of acute pancreatitis has been described.

Mailing Address: Dr. Jayanta Paul, MD., MBBS, DNB (Gastroenterology), S/o Jitendra Chandra Paul, J+B Lodge, Santosh Sarani, Banamali Pur, Barasat, Kolkata 700124, India; Phone: (+91) 83489840 88; e-mail: dr.jayantapaul@gmail.com 


\section{Introduction}

Course of acute pancreatitis (AP) is highly heterogeneous and at risk for development of persistent organ failure early in the course of severe AP. The incidence of acute pancreatitis is increasing worldwide, and it is one of the common gastrointestinal causes of hospital admission. The incidence of AP in USA, Scotland and Finland are 49.3, 41.9 and 46.6 per 100,000 populations, respectively (Toouli et al., 2002). In Europe and other developed nations like Hong Kong, more patients tend to have gallstone pancreatitis, whereas alcoholic pancreatitis is most common in United States. Alcohol and gallstones were the most common causes of acute pancreatitis in India (Mukherjee et al., 2017; Sharma et al., 2017; Negi et al., 2018). It is possible to identify the aetiology of AP in around $80 \%$ of cases and $20 \%$ is classified as idiopathic AP (Working Party of the British Society of Gastroenterology et al., 2005). Most patients with AP recover spontaneously with supportive measures in a short period of time but it has life-threatening potential in minority cases (Phillip et al., 2014). Over $80 \%$ of patients have mild, self-limiting AP and severe pancreatitis occurs in less than $20 \%$ of AP patients, characterized by a protracted clinical course, multiorgan failure, and pancreatic necrosis (Whitcomb, 2006). The mortality in severe acute pancreatitis is as high as $30 \%$ (Whitcomb, 2006), but the overall mortality in AP is 5\% (NICE, 2016). It is important to identify AP patients who are at risk for development of persistent organ failure early in the course of the disease (Otsuki et al., 2013). To decrease the mortality rate of the severe acute pancreatitis, it is important to evaluate the severity of AP early in the disease course and initiate appropriate treatment according to severity and aetiology (Juneja et al., 2010). Only clinical signs and symptoms are not reliable for severity assessment in majority of cases and they should be supported by objective measures (Takeda et al., 2010). Several scoring systems are useful for assessing the severity of AP and for deciding the treatment strategy and the need for transfer to a specialist unit (Takeda et al., 2010).

\section{Diagnosis}

The diagnostic probability of acute pancreatitis is based on the index of suspicion of clinician, which is largely based on the patient's history and examination findings (Figure 1). Revised Atlanta classification (2012) is used for diagnosis of acute pancreatitis which requires at least 2 of the following three criteria: 1 ) abdominal pain consistent with that of AP, 2) biochemical evidence of acute pancreatitis (serum amylase or lipase elevation $>3$ times the upper limit of normal), and 3) characteristics findings of AP seen in cross-sectional abdominal imaging (Banks et al., 2013).

Character of abdominal pain in acute pancreatitis

Abdominal pain consistent of acute pancreatitis means moderate to severe epigastric pain which is radiating to the back (seen in $40-70 \%$ of patients) and lasting for several hours to days (Tenner et al., 2013; Greenberg et al., 2016). Abdominal pain is the 
Acute pain abdomen (classical pancreatic pain)

(Upper abdominal pain which is radiating to the back and lasting for several hours to days; increased by eating or drinking; decreased by knee-to-chest/fetal position)

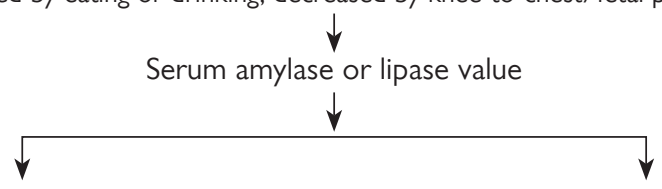

Elevated

( $>3$ times of upper limit)

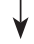

Acute pancreatitis

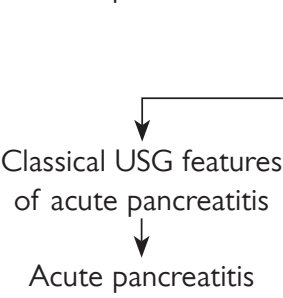

Normal or elevated but $<3$ times of upper limit

$\checkmark$

Cross-sectional abdominal imaging:

ultrasonography (UGS)

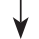

Inadequate features to diagnose acute pancreatitis

CT scan abdomen

Figure 1 - Diagnostic algorithm of acute pancreatitis.

cardinal symptom which occurs in about $95 \%$ of cases of AP. Typically pain involves the upper abdomen or more localized to epigastric area, or left upper quadrant. It is acute pain without prodromal symptoms which reaches maximum intensity within minutes to hours and tends to be moderately to intensely severe. The pain tends to be steady but intensity is increased by eating or drinking (especially alcohol). Knee-to-chest (fetal position) position decreases the pain intensity by decreasing the stretch of the pancreas. Due to retroperitoneal location of pancreas, pain is typically boring and deep in nature. It often radiates in to the lower thoracic region of the back. About $90 \%$ of patients of AP have nausea and vomiting due to peripancreatic inflammation involving posterior gastric wall which leads to gastroparesis and causing localized or generalized ileus (Cappell, 2008).

\section{Physical signs of acute pancreatitis}

Mild pancreatitis patients usually present with little abdominal tenderness on palpation but severe pancreatitis may present with severe abdominal tenderness on palpation, guarding generally localized to the upper abdomen and absence of bowel sounds due to paralytic ileus (Tenner et al., 2013; Greenberg et al., 2016). An around $60 \%$ patient with AP in early course develops low-grade fever due to peripancreatic inflammation but does not have evidence of infection. Cullen's and Turner signs are seen in about 3\% of AP patients and are associated with high mortality $(\sim 37 \%)$. These signs are usually associated with hemorrhagic pancreatitis but are not specific to haemorrhage (Meyers el., 1989; Mookadam and Cikes, 2005). 
Around 10-20\% AP patients have respiratory signs such as pleural effusion, left sided basal collapse, basal crepitations and wheezing (Baker, 2004).

Biochemical changes in acute pancreatitis (Table 1)

Table 1 - Biochemical changes in acute pancreatitis

\begin{tabular}{|c|c|c|c|}
\hline Test & $\begin{array}{l}\text { Specificity (SP) } \\
\text { and sensitivity } \\
\text { (SN) }\end{array}$ & Significances & $\begin{array}{l}\text { False positive/false } \\
\text { negative results }\end{array}$ \\
\hline $\begin{array}{l}\text { Serum } \\
\text { lipase }\end{array}$ & $\begin{array}{l}\text { Specificity is } \\
>95 \% \text { when } \\
\text { lipase value } \\
>600 \mathrm{IU} / \mathrm{I} \text {. } \\
\text { Overall (when } \\
\text { value }>3 \text { times } \\
\text { of ULN) SN and } \\
\text { SP are } 80 \text { to } 100 \% \\
\text { and } 50 \text { to } 99 \% \\
\text { respectively. }\end{array}$ & $\begin{array}{l}\text { A. Lipase has a higher } \\
\text { diagnostic accuracy } \\
\text { compared to amylase. } \\
\text { B. Elevated serum } \\
\text { triglyceride level does } \\
\text { not influence the serum } \\
\text { lipase level as happens } \\
\text { in the case of serum } \\
\text { amylase. } \\
\text { C. Pancreas is the only } \\
\text { source of lipase. }\end{array}$ & $\begin{array}{l}\text { False positive result can be } \\
\text { seen in following conditions: } \\
\text { 1. Inflammatory bowel disease } \\
\text { 2. Renal insufficiency } \\
\text { 3. Appendicitis } \\
\text { 4. Intestinal ischemia } \\
\text { 5. Intestinal obstruction } \\
\text { 6. Intestinal perforation } \\
\text { 7. Acute cholecystitis } \\
\text { 8. Furosemide use }\end{array}$ \\
\hline $\begin{array}{l}\text { Serum } \\
\text { amylase }\end{array}$ & $\begin{array}{l}\text { Serum amylase } \\
\text { cut-off level of } \\
1000 \text { IU/I has } \\
55-84 \% \text { sensitivity } \\
\text { and specificity up } \\
\text { to } 95 \% \text {. }\end{array}$ & $\begin{array}{l}\text { A. Serum amylase level } \\
\text { at least three times the } \\
\text { upper limit of normal } \\
\text { supports the diagnosis of } \\
\text { acute pancreatitis. } \\
\text { B. Synthesized by pancreas } \\
\text { and salivary glands and } \\
\text { in very small quantities } \\
\text { from other locations such } \\
\text { as fallopian tubes, testes, } \\
\text { lungs, thyroid, tonsils, } \\
\text { breast milk, sweat, tears, } \\
\text { and some malignant } \\
\text { neoplasm. } \\
\text { C. In acute pancreatitis, } \\
\text { serum amylase level } \\
\text { increases quickly within six } \\
\text { hours of onset of disease } \\
\text { and returns to normal } \\
\text { within } 3 \text { to } 5 \text { days, finally } \\
\text { is excreted by the kidney. }\end{array}$ & $\begin{array}{l}\text { False positive results can be } \\
\text { seen in following conditions: } \\
\text { 1. Macroamylasemia } \\
\text { 2. Renal failure } \\
\text { 3. Oesophageal perforation } \\
\text { 4. Mumps parotitis } \\
\text { 5. Pregnancy } \\
\text { 6. Chronic alcoholism } \\
\text { 7. Post coronary bypass } \\
\text { 8. Lactic acidosis } \\
\text { 9. Anorexia nervosa or bulimia } \\
\text { False negative results } \\
\text { (in } 19-32 \% \text { of cases)can be } \\
\text { seen in following conditions: } \\
\text { 1. Secondary to chronic alcohol } \\
\text { abuse due to pre-existing } \\
\text { pancreatic injury } \\
\text { 2. Hypertriglyceridemia due to } \\
\text { dilutional effects of the lipemia. }\end{array}$ \\
\hline
\end{tabular}




\begin{tabular}{|c|c|c|}
\hline $\begin{array}{l}\text { Trypsinogen } \\
\text { (TAP) }\end{array}$ & $\begin{array}{l}\text { Less commonly } \\
\text { used in routine } \\
\text { clinical practice } \\
\text { due to its low } \\
\text { sensitivity, } \\
\text { specificity and } \\
\text { limited availability. }\end{array}$ & $\begin{array}{l}\text { A. The negative predictive } \\
\text { value of urinary TAP is } \\
99 \% \text {, therefore negative } \\
\text { test result can exclude } \\
\text { diagnosis of acute } \\
\text { pancreatitis. } \\
\text { B. Both serum and } \\
\text { urine concentrations of } \\
\text { trypsinogen rise within } \\
\text { few hours of onset of } \\
\text { acute pancreatitis and } \\
\text { come to normal level } \\
\text { within } 3 \text { to } 5 \text { days. }\end{array}$ \\
\hline $\begin{array}{l}\text { Hepatic } \\
\text { trans- } \\
\text { aminases }\end{array}$ & & $\begin{array}{l}\text { Elevated in patients with acute pancreatitis caused by alcohol } \\
\text { abuse or biliary pancreatitis. } \\
\text { 1. Serum alanine aminotransferase (ALT) level higher than } \\
\text { threefold or more above normal suggests biliary rather than } \\
\text { alcoholic pancreatitis. } \\
\text { 2. ALT level higher than } 150 \mathrm{IU} / \mathrm{I} \text { has } 95 \% \text { positive predictive } \\
\text { value in diagnosing gallstone pancreatitis. }\end{array}$ \\
\hline $\begin{array}{l}\text { WBC } \\
\text { count, CRP }\end{array}$ & & $\begin{array}{l}\text { Both are elevated due to systemic inflammatory response } \\
\text { in early course of acute AP. However elevation of WBC } \\
\text { count and CRP after 7-10 days of onset (late phase of AP) } \\
\text { indicate infection. }\end{array}$ \\
\hline $\begin{array}{l}\text { Serum } \\
\text { calcium } \\
\text { and trigly- } \\
\text { ceride level }\end{array}$ & & Advised to identify underlying cause of acute pancreatitis. \\
\hline
\end{tabular}

\section{Serum lipase}

Due to its high sensitivity and specificity, serum lipase is the primary diagnostic serum marker of acute pancreatitis. The specificity (50\% to 99\%) and sensitivity (86\% to $100 \%$ ) of lipase are greater than amylase for diagnosis of AP (Gamaste, 1994). Lipase has a higher diagnostic accuracy compared to amylase as the half-life of elevated amylase is shorter than that of lipase (Matull et al., 2006) and the pancreas is the only source of lipase. The specificity of lipase is improved by increasing the threshold to at least three times the upper limit of the normal reference values (Calleja and Barkin, 1993). At lipase cut-off level of $600 \mathrm{IU} / \mathrm{I}$, reported specificity is above 95\% (Kylänpää-Bäck et al., 2002; Matull et al., 2006). Concentration of lipase in serum increases within 3-6 hours after onset of AP, peaks within 24 hours and stays around 1-2 weeks before it comes down to the normal level (Matull et al., 2006; Lippi et al., 2012). Lipase is preferred over amylase in routine clinical practice (Forsmark and Baillie, 2007). Elevated serum triglyceride level does not influence 
the serum lipase level as happens in the case of serum amylase. Some medical and surgical conditions such as inflammatory bowel disease, renal insufficiency, appendicitis, intestinal ischemia, obstruction, perforation, acute cholecystitis may give false positive result (Matull et al., 2006; Lippi et al., 2012; Meher et al., 2015). Drug such as furosemide also can increase serum lipase level (Matull et al., 2006).

\section{Serum amylase}

Amylase is a glycoside hydrolase primarily synthesized by pancreas and salivary glands and in very small quantities from other locations such as fallopian tubes, testes, lungs, thyroid, tonsils, breast milk, sweat, tears, and some malignant neoplasms. Electrophoresis shows that serum amylase is of two main types such as P-type amylase from the pancreas, and S-type amylase from the salivary glands. Serum amylase level at least three times the upper limit of normal supports the diagnosis of acute pancreatitis. In acute pancreatitis, serum amylase level increases quickly within six hours of onset of disease and returns to normal within 3 to 5 days, finally is excreted by the kidney (Smotkin and Tenner, 2002; Rau et al., 2005; Shah et al., 2010). Serum amylase activity is normal or low in 19-32\% of cases at the time of hospital admission, secondary to chronic alcohol abuse due to pre-existing pancreatic injury (Clavien et al., 1989; Matull et al., 2006) and hypertriglyceridemia due to dilutional effects of the lipemia (Yadav et al., 2002; Matull et al., 2006). Sensitivity and specificity of serum amylase value for diagnosis of AP depend on its threshold value, and a cut-off serum level of $1000 \mathrm{IU} / \mathrm{I}$ has $55-84 \%$ sensitivity and specificity up to 95\% (Pieper-Bigelow et al., 1990; Keim et al., 1998; Smith et al., 2005). Other than acute pancreatitis, several conditions increase serum amylase level such as macroamylasemia, renal failure, oesophageal perforation, mumps parotitis, pregnancy, chronic alcoholism, post coronary bypass, lactic acidosis, anorexia nervosa or bulimia (Pieper-Bigelow et al., 1990; Cappell, 2008). Serum amylase is being used since a long time for the diagnosis of AP because it is the only biochemical marker available in many small hospitals.

\section{Trypsinogen}

Trypsinogen (TAP) is useful as a diagnostic marker for acute pancreatitis due to their accuracy, but its use is limited by availability (Matull et al., 2006). Among two isoenzymes of trypsinogen, trypsinogen-2 shows considerably higher serum concentrations in AP (Petersson et al., 1999). Both serum and urine concentrations of trypsinogen rise within few hours of onset of acute pancreatitis and come to normal level within 3 to 5 days (Petersson et al., 1999; Matull et al., 2006; Lippi et al., 2012). Dipstick method to detect urinary trysinogen-2 may be devised for rapid detection of AP but this method is less commonly used in routine clinical practice due to its low sensitivity, specificity and limited availability (Kamer et al., 2007; Lippi et al., 2012). Early elevated levels of urinary TAP are associated with severe acute pancreatitis (Toouli et al., 2002). The negative predictive value of urinary TAP is 
$99 \%$, so negative test result can exclude diagnosis of acute pancreatitis (Kemppainen et al., 1997).

\section{Other biochemical markers}

Leukocytosis is common laboratory finding of AP in early course due to systemic inflammatory response but in later stage ( 7 to 10 days after onset of AP) it indicates infection. Hepatic transaminases level may be elevated in patients with pancreatitis caused by alcohol abuse or biliary pancreatitis. Around $20 \%$ of AP patients have jaundice and jaundice associated with pancreatitis in the absence of choledocholithiasis usually is related to hepatocellular involvement (McCollum and Jordan, 1975). Serum alanine aminotransferases (ALT) level higher than threefold or more above normal suggests biliary rather than alcoholic pancreatitis (Ammori et al., 2003) and ALT level higher than $150 \mathrm{IU} / \mathrm{I}$ has $95 \%$ positive predictive value in diagnosing gallstone pancreatitis (Tenner et al., 1994). Mild elevation of blood sugar level is also seen due to decreased insulin secretion and increased glucagon levels. Serum calcium and triglyceride level should be advised to identify underlying cause of acute pancreatitis.

Imagines for diagnosis of acute pancreatitis

According to the Revised Atlanta classification (2012), imaging is used in diagnosis of AP. Imaging is manifold to clarify the diagnosis of AP when the clinical picture is confusing (when abdominal pain is suggestive of acute pancreatitis but the serum amylase or lipase assay is less than 3 times the upper limit of normal) (Bollen, 2012).

Ultrasound is frequently used as the first investigation on admission although it has limited value in the diagnosis of pancreatitis or its complications (Koo et al., 2010) and may show pancreatic swelling but in only $25-50 \%$ of patients with acute pancreatitis, pancreas is visualised. Pancreas is obscured secondary to bowel gas in $35 \%$ cases during ultrasonography (Gamaste, 1994). The most common cause of acute pancreatitis is cholelithiasis followed by alcohol intake therefore to detect cholelithiasis transabdominal ultrasonography should be performed for all patients at admission (Van Santvoort et al., 2011; Working Group IAPAPAAPG, 2013). For the detection of cholelithiasis, sensitivity of abdominal ultrasonography is $95 \%$ but sensitive for the detection of choledocholithiasis (bile duct stone) is 50\% (O'Connor et al., 1986).

Among all imaging modalities, contrast enhanced CT (CECT) is the standard technique for overall assessment of acute pancreatitis and its sequelae (Fisher and Gardner, 2012; Johnson et al., 2014; Zhao et al., 2015). For visualization of pancreatic pathology, contrast enhanced computed tomography (CT scan) and magnetic resonance imaging (MRI) of the abdomen are best imaging modalities, although these investigations are not routinely indicated in patients with mild AP. CECT abdomen is more accurate than ultrasonography for detection of 
peripancreatic inflammation and intrapancreatic necrosis. CT abdomen should be done in patients who present with severe pancreatitis or present initially with mild to moderate pancreatitis but does not improve after several days of supportive therapy. However CECT is contraindicated in patients who have intravenous contrast allergy or renal insufficiency.

MRI abdomen is usually advised those who are pregnant (to avoid radiation from $\mathrm{CT}$ ), allergic to the contrast used for enhanced $\mathrm{CT}$, and have renal insufficiency (Zhao et al., 2015). Magnetic resonance cholangiopancreatography (MRCP) abdomen is also indicated in patients who have altered liver function tests (LFT) with suspected common bile duct stone or disease but ultrasonography is inconclusive.

Sensitivity of endoscopic ultrasound (EUS) is greater than MRCP for detection of common bile duct stone. EUS is usually advised in patients who are pregnant because of its relative safety during pregnancy and in patients who cannot undergo MRCP due to presence of internal metallic devices (Cappell, 2008). It is the least expensive initial investigation for the diagnostic evaluation of patients with idiopathic acute pancreatitis with gallbladder in situ (Wilcox and Kilgore, 2009).

Endoscopic retrograde cholangiopancreatography (ERCP) can be used with extreme caution in acute pancreatitis patients and should never be used as a first-line diagnostic tool in AP (Telem et al., 2009). ERCP should be performed only when the patient has acute pancreatitis with cholangitis secondary to choledocholithiasis and when patient with biliary pancreatitis is experiencing worsening jaundice and clinical deterioration despite maximal supportive therapy (Kapetanos, 2010). There is no indication for urgent ERCP in patients with mild pancreatitis without cholangitis (Kapetanos, 2010).

\section{Severity assessment}

15-20\% of acute pancreatitis patients develop severe disease and have prolonged hospital stay (Forsmark and Baillie, 2007; Tenner et al., 2013; Greenberg et al., 2016), and 20 to 30 percent of AP patients develop complications such as necrosis, organ failure, or both (Mayer et al., 1985; Thomson, 1985). It is very important to assess severity of acute pancreatitis as early as possible because morbidity and mortality of AP differ markedly between mild and severe disease (in mild disease $<5 \%$ vs. in severe disease $20-25 \%$ ) (Tandon, 2013). Detection of severity of AP is important for early recognition of pancreatic complications, therapeutic decisions, triage of patients to higher levels of care such as an ICU, and prognostication.

There are several clinical, biochemical, radiological markers and scoring systems (Table 2) are available to detect severity of AP but clinical monitoring is inadequate to detect severity and predicting the course of acute pancreatitis because about only 39 percent of severe cases can be detected by clinical assessment (Ranson, 1985). There are no "gold standard" prognostic score to predict severe acute pancreatitis (Leppäniemi et al., 2019). 


\section{Table 2 - Different scoring systems for severity assessment of acute pancreatitis (AP)}

\begin{tabular}{|c|c|}
\hline Scoring system & Interpretation and mortality (MT) \\
\hline $\begin{array}{l}\text { 1. Revised Atlanta } \\
\text { classification } \\
\text { (RAC) of acute } \\
\text { pancreatitis }\end{array}$ & $\begin{array}{l}\text { No organ failure and no systemic or local complications: mild acute } \\
\text { pancreatitis (AP) (MT: } 1-2 \%) \text {. } \\
\text { Transient organ failure (<48 hours) and/or local or systemic } \\
\text { complications: moderate AP (MT: } \sim 2 \%) \text {. } \\
\text { Persistent organ failure and/or local or systemic complications: severe } \\
\text { AP (MT: } 20-40 \%) \text {. }\end{array}$ \\
\hline $\begin{array}{l}\text { 2. Determinant } \\
\text { based classification } \\
\text { (DBC) of AP }\end{array}$ & $\begin{array}{l}\text { Mild AP: lacks of both (peri) pancreatic necrosis and organ failure. } \\
\text { Moderate AP: sterile (peri) pancreatic necrosis and/or transient organ } \\
\text { failure. } \\
\text { Severe AP: presence of either infected (peri) pancreatic necrosis or } \\
\text { persistent organ failure. } \\
\text { Critical acute AP: infected (peri) pancreatic necrosis and persistent organ } \\
\text { failure. }\end{array}$ \\
\hline $\begin{array}{l}\text { 3. Ranson's } \\
\text { criteria }\end{array}$ & $\begin{array}{l}\text { Score } \geq 3 \text { : severe pancreatitis likely and score < } 3 \text { : severe pancreatitis is } \\
\text { unlikely. } \\
\text { Score < 3: MT 0-3\%; score 3-5: MT 11-15\% and score } \geq 6 \text { : MT } 40 \% \text {. }\end{array}$ \\
\hline $\begin{array}{l}\text { 4. Modified } \\
\text { Ranson's criteria }\end{array}$ & It has 10 parameters to assess gallstone pancreatitis. \\
\hline $\begin{array}{l}\text { 5. BISAP (bedside } \\
\text { index of severity in } \\
\text { acute pancreatitis) } \\
\text { score }\end{array}$ & $\begin{array}{l}\text { Cut-off value of BISAP score for prediction of severe AP is } \geq 2 \text {. } \\
\text { MT is }<2 \% \text { when BISAP score } 0-2 \text { and }>15 \% \text { when BISAP score } 3-5 \text {. }\end{array}$ \\
\hline 6. APACHE II scale & $\begin{array}{l}\text { APACHE II score is > } 8 \text { points; it is classified as severe acute pancreatitis. } \\
\text { After } 48 \text { hours, the APACHE II score can predict the outcome in } 88 \% \text { of } \\
\text { acute pancreatitis cases. }\end{array}$ \\
\hline 7. Glasgow score & $\begin{array}{l}\text { There is a cut off for severe AP: } \geq 2 \text { points and scores above } 3 \text { also } \\
\text { indicate that the patient is likely to require admission to intensive care } \\
(I C U) \text {. }\end{array}$ \\
\hline $\begin{array}{l}\text { 8. The harmless } \\
\text { acute pancreatitis } \\
\text { (HAP) score }\end{array}$ & $\begin{array}{l}\text { HAP score is considered positive if patients have any of these three } \\
\text { criteria. } \\
\text { HAP score } 0 \text { indicates patients do not require early aggressive treatments } \\
\text { and advanced radiological screening during the initial stages of the AP. }\end{array}$ \\
\hline $\begin{array}{l}\text { 9. The new } \\
\text { Japanese severity } \\
\text { scoring system } \\
\text { for AP (Japanese } \\
\text { severity score for } \\
\text { acute pancreatitis) }\end{array}$ & $\begin{array}{l}\text { Severe AP is diagnosed when the total prognostic factor score is } \geq 3 \text {. } \\
\text { Prognostic factor score } \geq 4 \text { is the best cut-off value to identify patients } \\
\text { who were at risk for mortality. }\end{array}$ \\
\hline 10. PANC3 score & $\begin{array}{l}\text { The combination of the PANC3 variables was highly predictive of SAP. } \\
\text { ( } 96.43 \% \text { specificity, } 75 \% \text { sensitivity, } 80 \% \text { positive predictive value, and } \\
95.29 \% \text { negative predictive value to identify severe acute pancreatitis). }\end{array}$ \\
\hline
\end{tabular}




\begin{tabular}{|c|c|}
\hline 11. PANC4 score & $\begin{array}{l}\text { It needs further large studies to prove good results in large scale and its } \\
\text { use in clinical practice. }\end{array}$ \\
\hline $\begin{array}{l}\text { 12. CT severity } \\
\text { index }(\mathrm{CTSI})\end{array}$ & $\begin{array}{l}\text { Mild AP (CTSI: 0-3), moderate AP (CTSI: 4-6), severe AP } \\
\text { (CTSI: 7-10; MT 17\%) }\end{array}$ \\
\hline $\begin{array}{l}\text { 13. Modified } \\
\text { computed } \\
\text { tomography } \\
\text { severity index } \\
\text { (MCTSI) }\end{array}$ & $\begin{array}{l}\text { Mild AP (score: 0-2), moderate AP (score: 4-6), severe AP } \\
\text { (score: } 8-10 \text { ) }\end{array}$ \\
\hline
\end{tabular}

Revised Atlanta classification (RAC) of acute pancreatitis

This system classifies AP into three groups based on presence or absence of persistent organ failure and local and systemic complications. Mild AP is defined as no organ failure and no systemic or local complications, and is associated with rare mortality (1-2\%) (Triester and Kowdley, 2002). Moderately severe AP has transient organ failure (<48 hours) and/or local or systemic complications and is associated with a low mortality rate of approximately 2\% (Vege et al., 2009) and severe AP has persistent organ failure and/or local or systemic complications with a mortality rate of approximately 20-40\% (Sarr, 2013; Talukdar et al., 2014a; Meher et al., 2015). The modified Marshall scoring system is used in the Revised Atlanta classification as the primary method to detect organ failure and includes measurements from the respiratory $\left(\mathrm{PaO}_{2} / \mathrm{FiO}_{2}\right.$ ratio) (score 1: 301-400, score 2: 201-300, score 3: 101-200, score 4: $\leq 100$ ), cardiovascular (systolic blood pressure) (score 1: $<90 \mathrm{~mm} \mathrm{Hg}$ but responding to fluid resuscitation therapy, score 2: $<90 \mathrm{~mm} \mathrm{Hg}$ but not responding to fluid resuscitation therapy, score 3: $<90 \mathrm{~mm} \mathrm{Hg}$ and $\mathrm{pH}<7.3$, score 4: $<90 \mathrm{~mm} \mathrm{Hg}$ and $\mathrm{pH}<7.2$ ), and renal systems (creatinine value) (score 1: 1.5-1.8 mg/dl, score 2: 1.9-3.5 mg/dl, score 3: 3.6-4.9 $\mathrm{mg} / \mathrm{dl}$ ), with a score of 2 or higher for any system indicating organ failure (Marshall et al., 1995; Thoeni, 2012; Banks et al., 2013). Local complications are fluid collections (acute peripancreatic fluid collection, pancreatic pseudocyst, acute necrotic collection, and walled off necrosis), gastric outlet dysfunction, spleenic vein thrombosis, portal vein thrombosis, and colonic necrosis (Banks et al., 2013; Sarr, 2013). Systemic complication is defined as renal, circulatory, or respiratory organ failure or exacerbation of pre-existing comorbidities like coronary artery disease, congestive cardiac failure, chronic obstructive pulmonary disease, diabetes, and chronic liver disease due to acute pancreatitis (Sarr, 2013). The Revised Atlanta classification (RAC) divides course of AP into an early phase, usually lasting up to 1 week, followed by a late phase which is characterized by persistent signs and symptoms with systemic or local complications, occurring only in moderately severe and severe AP and lasting $>1$ week and can extend for months. 


\section{Determinant based classification (DBC) of AP}

The primary highlight of the determinant based classification (DBC) is the introduction of the new group called critical acute pancreatitis. The severity of AP is classified into four categories based on DBC (mild, moderate, severe, and critical AP). Mild AP lacks both (peri) pancreatic necrosis and organ failure. Moderate AP has sterile (peri) pancreatic necrosis and/or transient organ failure. Severe AP is defined as the presence of either infected (peri) pancreatic necrosis or persistent organ failure (Dellinger et al., 2012). When AP has both infected (peri) pancreatic necrosis and persistent organ failure, it is called critical acute pancreatitis. DBC system has less heterogeneity than RAC system with respect to classification of moderate acute pancreatitis, which should be noted when using RAC to classify acute pancreatitis (Qi et al., 2017).

\section{Ranson's criteria}

The Ranson's criterion is a scoring system to predict severity and mortality of acute pancreatitis. Dr. John Ranson, a surgeon introduced this criterion in 1974 in his article "Prognostic signs and the role of operative management in acute pancreatitis".

Variables in Ranson's criteria: the score takes 11 variables: 5 of which (patient older than 55 years, WBC count higher than $16,000 / \mu$ l, blood glucose level higher than $200 \mathrm{mg} / \mathrm{dl}$, serum LDH level higher than $350 \mathrm{lU} / \mathrm{I}$, AST level higher than $250 \mathrm{IU} / \mathrm{I}$ ) are measured at the time of admission while 6 of these (hematocrit fall of more than $10 \%$, BUN level increase by more than $8 \mathrm{mg} / \mathrm{dl}$, serum calcium level lower than $8 \mathrm{mg} / \mathrm{dl}, \mathrm{PaO}_{2}$ less than $60 \mathrm{~mm} \mathrm{Hg}$, base deficit higher than $4 \mathrm{mEq} / \mathrm{l}$, estimated fluid sequestration $>6$ liters) are measured $48 \mathrm{~h}$ after admission (Imrie, 2003).

Interpretations of Ranson's criteria: if the score $\geq 3$, severe pancreatitis likely and if the score $<3$, severe pancreatitis is unlikely (Ranson, 1982; Ducarme et al., 2014). The mortality rises with increasing total scores, $0-3 \%$ mortality in patients with a score $<3,11-15 \%$ in a score $\geq 3$, and $40 \%$ when the score is $\geq 6$ (Banks et al., 2006).

Limitations of Ranson's criteria: 1) The Ranson score is valid only at 48 hours after onset of AP. 2) Other scoring systems are superior to Ranson's criteria in either sensitivity or specificity. Sensitivity of Ranson's score is only $73 \%$ and the specificity is $77 \%$ for predicting mortality. 3) Ranson's criteria cannot be used for a paediatric or adolescent population because Ranson et al. included an age range of approximately 30 to 75 years old in their study (Lautz et al., 2011). 4) Threshold for an abnormal value for alcoholic and gall stone pancreatitis are not same. 5) It is a poor predictor of severity (Papachristou et al., 2010).

\section{Modified Ranson's criteria}

The Ranson's criteria are used to score alcoholic pancreatitis while the modified criteria including 10 parameters are used to score gallbladder pancreatitis (Shah 
et al., 2017; Hagjer and Kumar, 2018; Waller et al., 2018). It has 10 parameters to assess gallstone pancreatitis. Five parameters assessed on admission and the other five at the 48-hour after admission.

\section{BISAP (bedside index of severity in acute pancreatitis) score}

This scoring system is easy to use but has only been validated to predict mortality (Papachristou et al., 2010; Gao et al., 2015). BISAP scoring system is not inferior to Ranson's scoring system to predict severity of acute pancreatitis (Parimala and Beulah, 2019). Ranson's scores identify severe acute pancreatitis (SAP) more accurately than BISAP scores ( $97.4 \%$ vs. $69.2 \%$ ) and specificity of both scores predicts SAP almost equally (78.4\% vs. $77.8 \%$ ) (Arif et al., 2019). However another study (systemic review and meta-analysis) showed that compared with BISAP score, the Ranson criteria and APACHE II score have higher sensitivity and lower specificity to predict both severe acute pancreatitis and mortality (Gao et al., 2015).

This score is one of the most accurate and applicable in everyday clinical practice because of the simplicity and the capability to predict severity, death, and organ failure (Leppäniemi et al., 2019). BISAP score has fewer variables than Ranson's score and APACHE II score and is cost effective and can be calculated in emergency setting, so; there is no time delay (Arif et al., 2019). It is a reliable scoring system to predict severity and organ failure within 24 hours of admission (Kaushik et al., 2017).

BISAP scoring system includes following components: BUN $>25 \mathrm{mg} / \mathrm{dl}$, impaired mental status (Glasgow coma scale $<15$ ), SIRS (it is defined as two or more of the following: 1) temperature of $>38.0^{\circ} \mathrm{C}$ or $<36.0^{\circ} \mathrm{C}$, 2) respiratory rate $>24$ breaths $/ \mathrm{min}$ or $\mathrm{PaCO}_{2}<32 \mathrm{~mm} \mathrm{Hg}$, 3) pulse $>90$ beats/min, 4) WBC 12,000 cells $/ \mathrm{mm}^{3}$ or $>10 \%$ immature bands), age $>60$ years, pleural effusion detected on chest radiograph.

Cut-off value of BISAP score for prediction of severe AP is $\geq 2$ (Cho et al., 2015). Another meta-analysis showed that a BISAP score of 3 is reliable to identify the high-risk AP (Gao et al., 2015). BISAP score showed mortality of $<2 \%$ when score: $0-2$ and $>15 \%$ when score: $3-5$ (Wu et al., 2018). One study from China demonstrated that the best cut-off value for BISAP is 2 for predicting pancreatic necrosis and organ failure, and 3 for predicting mortality (Chen et al., 2013).

\section{APACHE II scale}

It can be performed on admission and re-evaluated at any time during the hospitalization. APACHE II score includes 11 physiologic components plus patient's age, organ insufficiency, neurologic status and postoperative state (Cappell, 2008). Due to its complicated nature and requirement of long list of parameters, it is not practical to use in smaller hospitals with limited staff and expertise. After 48 hours, the APACHE II score can predict the outcome in $88 \%$ of acute pancreatitis cases (Larvin and McMahon, 1989). 
According to Atlanta Symposium (1992) (Bradley, 1993) and the World Congress of Gastroenterology Guidelines (2002) (Toouli et al., 2002), when APACHE II score is $>8$ points; it is classified as severe acute pancreatitis.

\section{Glasgow score}

The Glasgow pancreatitis score was created by Blamey et al. in 1984 as a prognostic factor to identify the severity of AP. It is also called Imrie score and includes eight of 11 variables used in the Ranson's criteria, and can be performed within 24 hours from admission for patients.

This scoring system includes following components: 1) age $>55$ years, 2) serum albumin $<32 \mathrm{~g} / \mathrm{l}(3.2 \mathrm{~g} / \mathrm{dl}), 3)$ arterial $\mathrm{PO}_{2}$ on room air $\left.<8 \mathrm{kPa}(60 \mathrm{~mm} \mathrm{Hg}), 4\right)$ serum calcium $<2$ mmols $/ \mathrm{l}(8 \mathrm{mg} / \mathrm{dl}), 5)$ blood glucose $>10.0 \mathrm{mmols} / \mathrm{l}$ $(180 \mathrm{mg} / \mathrm{dl}), 6)$ serum $\mathrm{LDH}>600$ units $/ \mathrm{l}, 7)$ serum urea nitrogen $>16.1 \mathrm{mmols} / \mathrm{I}$ (45 mg/dl), 8) WBC count $>15 \times 10^{9} / \mathrm{l}\left(15 \times 10^{3} /\right.$ microlitre).

Each variable in this scoring system has 1 point. Cut-off for severe AP is $\geq 2$ points, and scores above 3 also indicate that the patient is likely to require admission to intensive care (ICU) (Blamey et al., 1984; Taylor et al., 2005; Mounzer et al., 2012).

The harmless acute pancreatitis (HAP) score

This is a simple and useful scoring algorithm which requires three parameters to identify patients with nonsevere AP. HAP score can predict a non-severe course within 30-60 min of admission (Lankisch et al., 2009; Talukdar et al., 2014b). This scoring system has high specificity (97\%) and positive predictive value $(98 \%)$ and allows physicians to detect AP patients quickly who do not require ICU care, and potentially those who do not require inpatient treatment at all, and reduce hospital cost (Lankisch et al., 2009).

HAP score includes three parameters: rebound abdominal tenderness and/or guarding, serum creatinine serum creatinine of $>2 \mathrm{mg} / \mathrm{dl}$, and hematocrit of $>43$ for male and $>39.6$ for female patients, at the time of admission. HAP score is considered positive if patients have any of these three criteria. Presence of each of these is awarded a score of 1 , thus minimum score is 0 and a maximum score is 3 (Talukdar et al., 2014a; Sayraç et al., 2018). HAP score 0 indicates patients do not require early aggressive treatments and advanced radiological screening during the initial stages of the AP (Sayraç et al., 2018).

The new Japanese severity scoring system for AP (Japanese severity score for acute pancreatitis)

This score has good predictive value for in-hospital mortality of acute pancreatitis patients, and is useful for severity assessment of AP at the initial stage of hospital admission (Hamada et al., 2013). It includes nine clinical and biochemical parameters and total score using a scale of 0-9 (Yokoe et al., 2015). 
Based on the Japanese severity criteria, severe AP is diagnosed when the total prognostic factor score is $\geq 3$ or the contrast-enhanced CT grade is $\geq 2$ (Ikeura et al., 2017). Prognostic factor score $\geq 4$ is the best cut-off value to identify patients who were at risk for mortality (Ikeura et al., 2017). The Japanese severity scoring system can be considered non-inferior to Ranson's score, Glasgow score, and APACHE II score for predicting mortality (Ueda et al., 2009; Hamada et al., 2013).

\section{PANC3 score}

This scoring system is simple, easy to assess, readily available, and economic. It includes three factors: serum hematocrit greater than $44 \mathrm{mg} / \mathrm{dl}$, a body mass index (BMI) greater than $30 \mathrm{mg} / \mathrm{kg}$, and a chest $X$-ray which reveals a pleural effusion (Brown et al., 2007). According to Brown et al. (2007), serum hematocrit is the strongest predictor of SAP and found that all three factors combined had a post-test likelihood ratio of $99 \%$ of developing severe acute pancreatitis. The combination of the three variables is highly predictive of SAP. PANC3 score has $96.43 \%$ specificity, $75 \%$ sensitivity, $80 \%$ positive predictive value, and $95.29 \%$ negative predictive value to identify severe acute pancreatitis (Shah et al., 2017). Another study showed that PANC3 score has sensitivity of $33 \%$ and specificity of 100\% (Borges et al., 2017).

PANC4 score

PANC4 criterion (two PANC3 markers + urea + platelets / leukocytes) proposed by Borges et al. (2017) is a score for the prognosis and severity of acute pancreatitis, but it needs further large studies to prove good results in large scale and its use in clinical practice.

\section{Amylase and BMI (CAB) score}

It is developed to identify patients most likely to develop severe AP based on the percentage changes in serum level of amylase during the first 2 days after admission to the hospital and BMI (Kumaravel et al., 2015).

\section{Single markers for predicting ASP}

1) On admission, hematocrit value $\geq 44 \%$ or failure of the hematocrit to decrease at 24 hours after admission is an indicative of SAP in the early stage of the disease (Berger and Rau, 2007). Absence of hemoconcentration on admission has a high negative predictive value for the necrosis development after AP (Gardner et al., 2006). 2) Serum creatinine is a predictor for pancreatic necrosis and an estimated glomerular filtration rate (GFR) $<90 \mathrm{ml} / \mathrm{min}$ per $1.73 \mathrm{~m}^{2}$ on admission can predict pancreatic necrosis (Muddana et al., 2009; Lipinski et al., 2013). 3) Rise in BUN $>1.8 \mathrm{mmol} / \mathrm{I}$ after 48 hours have a high predictive value as a single parameter SAP (Wu et al., 2011). 4) Rise of C- reactive protein (CRP) $>90 \mathrm{mg} / \mathrm{dl}$ from admission or an absolute value of $>190 \mathrm{mg} / \mathrm{dl}$ at $48 \mathrm{~h}$ predicts severe AP with the greatest accuracy (Stirling et al., 2017). C-reactive protein $>150 \mathrm{mg} / \mathrm{l}$ can predict 
complications in acute pancreatitis. 5) Procalcitonin (PCT) has been proposed to be useful marker for the detection of bacterial contamination of pancreatic necrosis (Rau et al., 1997) and a rapid semiquantitative PCT-assay is suggested to be valuable in differentiating severe AP from and mild cases (Wereszczynska et al., 1998). 6) Serum amylase and lipase are poor predictors of severity of AP (Swaroop et al., 2004). 7) Blood glucose concentration $<6.9 \mathrm{mmol} / \mathrm{l}$ on admission has a high negative predictive value (92\%) for pancreatic necrosis and also can serve as a predictor for severity of AP (Lankisch et al., 2001; Rajaratnam and Martin, 2006).

\section{CT severity index (CTSI)}

Optimal timing for initial CT assessment in AP is at least 72-96 hours after onset of symptoms. Recommendation is to perform multidetector $\mathrm{CT}$ with thin collimation and slice thickness (i.e. $5 \mathrm{~mm}$ or less), $100-150 \mathrm{ml}$ of non-ionic intra-venous contrast material at a rate of $3 \mathrm{ml} / \mathrm{s}$, during the pancreatic and/or portal venous phase (i.e. 50-70 seconds delay) (Working Group IAPAPAAPG, 2013).

The Balthazar score (1985) categorizes patients with AP into 5 groups (A to E) according to pancreatic and peripancreatic changes diagnosed by non-contrast $\mathrm{CT}$ abdomen (Balthazar et al., 1985). The use of CECT to localization of site and/or extent of pancreatic necrosis enhances the accuracy in prediction of outcome and high CTSI score correlates with worsening severity and prognosis, pancreatic infection (Balthazar et al., 1990; Simchuk et al., 2000). CTSI includes Balthazar score and extent of pancreatic necrosis (score 0 : no necrosis, score 1: $<30 \%$ necrosis, score 2: $30-50 \%$ necrosis and score 3: > 50\% necrosis).

CT severity index of 0 or 1 exhibits $0 \%$ mortality rate and no morbidity, while patients with CTSI of 2 has no mortality and $4 \%$ morbidity rate, and CTSI of 7-10 has a $17 \%$ mortality rate and $92 \%$ complication rate (Balthazar et al., 1990). Depending on score, pancreatitis is divided into mild (score: $0-3$ ), moderate (score: 4-6), severe (score: 7-10) (Balthazar et al., 1990).

Modified computed tomography severity index (MCTSI)

This index was developed on 2004. It includes pancreatic swelling or fat stranding, pancreatic collection(s), presence and extent of parenchymal necrosis, extrapancreatic complications including vascular, parenchymal, gastrointestinal organs and pleural effusion and ascites.

Score ranges from 0 to 10 . Depending on score, pancreatitis is divided into mild (score: 0-2), moderate (score: 4-6), severe (score: 8-10) (Mortele et al., 2004).

The MCTSI correlates more closely with patient outcome measures than the CTSI, with similar inter-observer variability (Sahu et al., 2017). MCTSI has a higher sensitivity but lower specificity than CTSI in differentiating mild from moderate and severe acute pancreatitis and also showed significant correlation with clinical outcome parameters, and good concordance with revised Atlanta classification grading of severity (Sahu et al., 2017). 


\section{Others radiological index}

Several other scores such as pancreatic size index (PSI), mesenteric edema and peritoneal fluid (MOP) score, extrapancreatic (EP) score, extrapancreatic inflammation on CT (EPIC) score, and MR severity index (MRSI) have been evaluated but none of these radiological scoring system were shown to be superior to clinical scoring systems (Tang et al., 2011; Bollen et al., 2012).

\section{Conclusion}

Acute pancreatitis is a potentially fatal disease, with mortality rates ranging from 0 to 25 percent, depending on severity. Therefore, early diagnosis of AP and severity assessment is important part of management. Revised Atlanta classification (2012) is commonly used for diagnosis of acute pancreatitis in day to day clinical practice. Once the diagnosis of AP is made, clinical efforts should simultaneously concentrate on investigating for the underlying aetiology and to find out severity of disease. In every-day clinical practice, Revised Atlanta classification system, BISAP score, HAP score, CT severity index can be used to assess severity of AP because these scoring systems can be measured at bedside and needs limited components. Severity assessment is initial main part of AP management because treatment of AP depends on grade of severity and aetiology.

\section{References}

Ammori, B. J., Boreham, B., Lewis, P., Roberts, S. A. (2003) The biochemical detection of biliary etiology of acute pancreatitis on admission: a revisit in the modern era of biliary imaging. Pancreas 26, e32-e35.

Arif, A., Jaleel, F., Rashid, K. (2019) Accuracy of BISAP score in prediction of severe acute pancreatitis.

Pak. J. Med. Sci. 35, 1008-1012.

Baker, S. (2004) Diagnosis and management of acute pancreatitis. Crit. Care Resusc. 6, 17-27.

Balthazar, E. J., Ranson, J. H., Naidich, D. P., Megibow, A. J., Caccavale, R., Cooper, M. M. (1985) Acute pancreatitis: prognostic value of CT. Radiology 156, 767-772.

Balthazar, E., Robinson, D., Megibow, A., Ranson, J. H. (1990) Acute pancreatitis: Value of CT in establishing prognosis. Radiology 174, 331-336.

Banks, P. A., Freeman, M. L.; Practice Parameters Committee of the American College of Gastroenterology (2006) Practice guidelines in acute pancreatitis. Am. J. Gastroenterol. 101, 2379-2400.

Banks, P. A., Bollen, T. L., Dervenis, C., Gooszen, H. G., Johnson, C. D., Sarr, M. G., Tsiotos, G. G., Vege, S. S.; Acute Pancreatitis Classification Working Group (2013) Classification of acute pancreatitis-2012: Revision of the Atlanta classification and definitions by international consensus. Gut 62, 102-111.

Berger, H. G., Rau, B. M. (2007) Severe acute pancreatitis: clinical course and management. World J. Gastroenterol. 13, 5043-5051.

Blamey, S. L., Imrie, C. W., O’Neill, J., Gilmour, W. H., Carter, D. C. (1984) Prognostic factors in acute pancreatitis. Gut 5, 1340-1346.

Bollen, T. L. (2012) Imaging of acute pancreatitis: update of the revised Atlanta classification. Radiol. Clin. North Am. 50, 429-445.

Bollen, T. L., Singh, V. K., Maurer, R., Repas, K., van Es, H. W., Banks, P. A., Mortele, K. J. (2012) A comparative evaluation of radiologic and clinical scoring systems in the early prediction of severity in acute pancreatitis. Am. J. Gastroenterol. 107, 612-619. 
Borges, T. A., Franzon, O., Mello, A. L. P. (2017) Analysis of new inflammatory markers in acute pancreatitis and confection of new prognostic definition model: Panc 4. EC Gastroenterol. Dig. Syst. 2, 240-246.

Bradley, E. L. $3^{\text {rd }}$ (1993) A clinically based classification system for acute pancreatitis. Summary of the International Symposium on Acute Pancreatitis, Atlanta, Ga, September 11 through 13, 1992. Arch. Surg. 128, 586-590.

Brown, A., James-Stevenson, T., Dyson, T., Grunkenmeier, D. (2007) The panc 3 score: A rapid and accurate test for predicting severity on presentation in acute pancreatitis. J. Clin. Gastroenterol. 41, 855-858.

Calleja, G. A., Barkin, J. S. (1993) Acute pancreatitis. Med. Clin. North Am. 77, 1037-1056.

Cappell, M. S. (2008) Acute pancreatitis: Etiology, clinical presentation, diagnosis, and therapy. Med. Clin. North Am. 92, 889-923.

Chen, L., Lu, G., Zhou, Q., Zhan, Q. (2013) Evaluation of the BISAP score in predicting severity and prognoses of acute pancreatitis in Chinese patients. Int. Surg. 98, 6-12.

Cho, J. H., Kim, T. N., Chung, H. H., Kim, K. H. (2015) Comparison of scoring systems in predicting the severity of acute pancreatitis. World J. Gastroenterol. 21, 2387-2394.

Clavien, P. A., Robert, J., Meyer, P., Borst, F., Hauser, H., Herrmann, F., Dunand, V., Rohner, A. (1989) Acute pancreatitis and normoamylasemia. Not an uncommon combination. Ann. Surg. 210, 614-620.

Dellinger, E. P., Forsmark, C. E., Layer, P., Lévy, P., Maraví-Poma, E., Petrov, M. S., Shimosegawa, T., Siriwardena, A. K., Uomo, G., Whitcomb, D. C., Windsor, J. A.; Pancreatitis Across Nations Clinical Research and Education Alliance (2012) Determinant-based classification of acute pancreatitis severity: an international multidisciplinary consultation. Ann. Surg. 256, 875-880.

Ducarme, G., Marie, F., Chatel, P., Luton, D., Hammel, P. (2014) Acute pancreatitis during pregnancy: a review. J. Perinatol. 34, 87-94.

Fisher, J. M., Gardner, T. B. (2012) The "golden hours" of management in acute pancreatitis. Am. J.

Gastroenterol. 107, 1146-1150.

Forsmark, C. E., Baillie, J. (2007) AGA Institute technical review on acute pancreatitis. Rev. Gastroenterol. Mex. 72, 257-285.

Gamaste, V. V. (1994) Diagnostic tests for acute pancreatitis. Gastroenterologist 2, 119-130.

Gao, W., Yang, H. X., Ma, C. E. (2015) The value of BISAP score for predicting mortality and severity in acute pancreatitis: a systematic review and meta-analysis. PLoS One 10, e0130412.

Gardner, T., Olenec, C., Chertoff, J., Mackenzie, T. A., Robertson, D. J. (2006) Hemoconcentration and pancreatic necrosis: further defining the relationship. Pancreas 33, 169-173.

Greenberg, J. A., Hsu, J., Bawazeer, M., Marshall, J., Friedrich, J. O., Nathens, A., Coburn, N., May, G. R., Pearsall, E., McLeod, R. S. (2016) Clinical practice guideline: management of acute pancreatitis. Can. J. Surg. 59, 128-140.

Hagjer, S., Kumar, N. (2018) Evaluation of the BISAP scoring system in prognostication of acute pancreatitis A prospective observational study. Int. J. Surg. 54, 76-81.

Hamada, T., Yasunaga, H., Nakai, Y., Isayama, H., Horiguchi, H., Fushimi, K., Koike, K. (2013) Japanese severity score for acute pancreatitis well predicts in-hospital mortality: a nationwide survey of 17,901 cases. J.

Gastroenterol. 48, 1384-1391.

Ikeura, T., Horibe, M., Sanui, M., Sasaki, M., Kuwagata, Y., Nishi, K., Kariya, S., Sawano, H., Goto, T., Hamada, T., Oda, T., Yasuda, H., Ogura, Y., Miyazaki, D., Hirose, K., Kitamura, K., Chiba, N., Ozaki, T., Yamashita, T., Koinuma, T., Oshima, T., Yamamoto, T., Hirota, M., Yamamoto, S., Oe, K., Ito, T., Iwasaki, E., Kanai, T., Okazaki, K., Mayumi, T. (2017) Validation of the efficacy of the prognostic factor score in the Japanese severity criteria for severe acute pancreatitis: A large multicenter study. United European Gastroenterol. J. 5, 389-397.

Imrie, C. W. (2003) Prognostic indicators in acute pancreatitis. Can. J. Gastroenterol. 17, 325-328. 
Johnson, C. D., Besselink, M. G., Carter, R. (2014) Acute pancreatitis. BMJ 349, g4859.

Juneja, D., Gopal, P. B., Ravula, M. (2010) Scoring systems in acute pancreatitis: Which one to use in intensive care units? J. Crit. Care 25, 358.e9-358.e15.

Kamer, E., Unalp, H. R., Derici, H., Tansug, T., Onal, M. A. (2007) Early diagnosis and prediction of severity in acute pancreatitis using the urine trypsinogen-2 dipstick test: a prospective study. World J. Gastroenterol. 13, 6208-6212.

Kapetanos, D. J. (2010) ERCP in acute biliary pancreatitis. World J Gastrointest Endosc. 2, 25-28.

Kaushik, M. R., Dubey, A. P., Jain, R., Pathak, A. (2017) Prospective evaluation of the BISAP score and its correlation with Marshall score in predicting severity of organ failure in acute pancreatitis. Int. J. Adv. Med. 4, 534-539.

Keim, V., Teich, N., Fiedler, F., Hartig, W., Thiele, G., Mössner, J. (1998) A comparison of lipase and amylase in the diagnosis of acute pancreatitis in patients with abdominal pain. Pancreas 16, 45-49.

Kemppainen, E. A., Hedstrom, J., Puolakkainen, P., Sainio, V. S., Haapiainen, R. K., Perhoniemi, V., Osman, S., Kivilaakso, E. O., Stenman, U. H. (1997) Rapid measurement of urinary trypsinogen-2 as a screening test for acute pancreatitis. N. Engl. J. Med. 336, 1788-1793.

Koo, B. C., Chinogureyi, A., Shaw, A. S. (2010) Imaging acute pancreatitis. Br. J. Radiol. 83, 104-112.

Kumaravel, A., Stevens, T., Papachristou, G. I., Muddana, V., Bhatt, A., Lee, P. J., Holmes, J., Lopez, R., Whitcomb, D. C., Parsi, M. A. (2015) A model to predict the severity of acute pancreatitis based on serum level of amylase and body mass index. Clin. Gastroenterol. Hepatol. 13, 1496-1501.

Kylänpää-Bäck, M. L., Kemppainen, E., Puolakkainen, P., Hedström, J., Haapiainen, R., Korvuo, A., Stenman, U. H. (2002) Comparison of urine trypsinogen-2 test strip with serum lipase in the diagnosis of acute pancreatitis. Hepatogastroenterology 49, 1130-1134.

Lankisch, P. G., Blum, T., Bruns, A., Dröge, M., Brinkmann, G., Struckmann, K., Nauck, M., Maisonneuve, P., Lowenfels, A. B. (2001) Has blood glucose level measured on admission to hospital in a patient with acute pancreatitis any prognostic value? Pancreatology 1, 224-229.

Lankisch, P. G., Weber-Dany, B., Hebel, K., Maisonneuve, P., Lowenfels, A. B. (2009) The harmless acute pancreatitis score: A clinical algorithm for rapid initial stratification of nonsevere disease. Clin. Gastroenterol. Hepatol. 7, 702-705.

Larvin, M., McMahon, M. J. (1989) APACHE-II score for assessment and monitoring of acute pancreatitis. Lancet 2, 201-205.

Lautz, T. B., Chin, A. C., Radhakrishnan, J. (2011) Acute pancreatitis in children: Spectrum of disease and predictors of severity. J. Pediatr. Surg. 46, 1144-1149.

Leppäniemi, A., Tolonen, M., Tarasconi, A., Segovia-Lohse, H., Gamberini, E., Kirkpatrick, A. W., Ball, C. G., Parry, N., Sartelli, M., Wolbrink, D., van Goor, H., Baiocchi, G., Ansaloni, L., Biffl, W., Coccolini, F., Saverio, S. D., Kluger, Y., Moore, E., Catena, F. (2019) 2019 WSES guidelines for the management of severe acute pancreatitis. World J. Emerg. Surg. 14, 27.

Lipinski, M., Rydzewski, A., Rydzewska, G. (2013) Early changes in serum creatinine level and estimated glomerular filtration rate predict pancreatic necrosis and mortality in acute pancreatitis: Creatinine and eGFR in acute pancreatitis. Pancreatology 13, 207-211.

Lippi, G., Valentino, M., Cervellin, G. (2012) Laboratory diagnosis of acute pancreatitis: In search of the Holy Grail. Crit. Rev. Clin. Lab. Sci. 49, 18-31.

Marshall, J. C., Cook, D. J., Christou, N. V., Bernard, G. R., Sprung, C. L., Sibbald, W. J. (1995) Multiple organ dysfunction score: A reliable descriptor of a complex clinical outcome. Crit. Care Med. 23, 1638-1652.

Matull, W. R., Pereira, S. P., O’Donohue, J. W. (2006) Biochemical markers of acute pancreatitis. J. Clin. Pathol. 59, 340-344. 
Mayer, A. D., McMahon, M. J., Corfield, A. P., Cooper, M. J., Williamson, R. C., Dickson, A. P., Shearer, M. G., Imrie, C. W. (1985) Controlled clinical trial of peritoneal lavage for the treatment of severe acute pancreatitis. N. Engl. J. Med. 312, 399-404.

McCollum, W. B., Jordan, P. H. (1975) Obstructive jaundice in patients with pancreatitis without associated biliary tract disease. Ann. Surg. 182, 116-120.

Meher, S., Mishra, T. S., Sasmal, P. K., Rath, S., Sharma, R., Rout, B., Sahu, M. K. (2015) Role of biomarkers in diagnosis and prognostic evaluation of acute pancreatitis. J. Biomark. 2015, 519534.

Meyers, M. A., Feldberg, M. A., Oliphant, M. (1989) Grey Turner's sign and Cullen's sign in acute pancreatitis. Gastrointest. Radiol. 14, 31-37.

Mookadam, F., Cikes, M. (2005) Images in clinical medicine. Cullen's and Turner's signs. N. Engl. J. Med. 353 , 1386.

Mortele, K. J., Wiesner, W., Intriere, L., Shankar, S., Zou, K. H., Kalantari, B. N., Perez, A., vanSonnenberg, E., Ros, P. R., Banks, P. A., Silverman, S. G. (2004) A modified CT severity index for evaluating acute pancreatitis: improved correlation with patient outcome. AJR Am. J. Roentgenol. 183, 1261-1265.

Mounzer, R., Langmead, C. J., Wu, B. U., Evans, A. C., Bishehsari, F., Muddana, V., Singh, V. K., Slivka, A., Whitcomb, D. C., Yadav, D., Banks, P. A., Papachristou, G. I. (2012) Comparison of existing clinical scoring systems to predict persistent organ failure in patients with acute pancreatitis. Gastroenterology 142, 1476-1482.

Muddana, V., Whitcomb, D. C., Khalid, A., Slivka, A., Papachristou, G. I. (2009) Elevated serum creatinine as a marker of pancreatic necrosis in acute pancreatitis. Am. J. Gastroenterol. 104, 164-170.

Mukherjee, D., Bhakta, S., Lahiry, S., Sinha, R. (2017) Demographic profile of acute pancreatitis in Eastern India: a single centre experience. Asian J. Med. Sci. 8, 24-29.

Negi, N., Mokta, J., Sharma, B., Sharma, R., Jhobta, A., Bodh, V., Ranjan, A. (2018) Clinical profile and outcome of acute pancreatitis: A hospital-based prospective observational study in Subhimalayan state. J. Assoc. Physicians India 66, 22-24.

NICE (2016) Pancreatitis: Diagnosis and Management. National Institute for Health and Care Excellence, London.

O’Connor, H. J., Hamilton, I., Ellis, W. R., Watters, J., Lintott, D. J., Axon, A. T. (1986) Ultrasound detection of choledocholithiasis: Prospective comparison with ERCP in the postcholecystectomy patient. Gastrointest. Radiol. 11, 161-164.

Otsuki, M., Takeda, K., Matsuno, S., Kihara, Y., Koizumi, M., Hirota, M., Ito, T., Kataoka, K., Kitagawa, M., Inui, K., Takeyama, Y. (2013) Criteria for the diagnosis and severity stratification of acute pancreatitis. World J. Gastroenterol. 19, 5798-5805.

Papachristou, G. I., Muddana, V., Yadav, D., O’Connell, M., Sanders, M. K., Slivka, A., Whitcomb, D. C. (2010) Comparison of BISAP, Ranson's, APACHE-II, and CTSI scores in predicting organ failure, complications, and mortality in acute pancreatitis. Am. J. Gastroenterol. 105, 435-441.

Parimala, Beulah, P. (2019) Comparative study between BISAP score and RANSON score in predicting severity of acute pancreatitis. IAIM 6, 62-66.

Petersson, U., Appelros, S., Borgstrom, A. (1999) Different patterns in immunoreactive anionic and cationic trypsinogen in urine and serum in acute pancreatitis. Int. J. Pancreatol. 25, 165-170.

Phillip, V., Steiner, J. M., Algül, H. (2014) Early phase of acute pancreatitis: assessment and management. World J. Gastrointest. Pathophysiol. 5, 158-168.

Pieper-Bigelow, C., Strocchi, A., Levitt, M. D. (1990) Where does serum amylase come from and where does it go? Gastroenterol. Clin. North Am. 19, 793-810.

Qi, B., Cao, F., Liu, J., Liu, D., Li, A., Liang, K., Li, F. (2017) Determinant-based classification and revised 
Atlanta classification: Differences between in categorization of moderate acute pancreatitis. Int. J. Clin. Exp. Med. 10, 12532-12538.

Rajaratnam, S. G., Martin, I. G. (2006) Admission serum glucose level: An accurate predictor of outcome in gallstone pancreatitis. Pancreas 33, 27-30.

Ranson, J. H. (1982) Etiological and prognostic factors in human acute pancreatitis: a review. Am. J. Gastroenterol. 7, 633-638.

Ranson, J. H. (1985) Risk factors in acute pancreatitis. Hosp. Pract. (Off. Ed.) 20, 69-73.

Rau, B., Steinbach, G., Gansauge, F., Mayer, J. M., Grünert, A., Beger, H. G. (1997) The potential role of procalcitonin and interleukin 8 in the prediction of infected necrosis in acute pancreatitis. Gut 41, 832-840.

Rau, B. M., Kruger, C. M., Schilling, M. K. (2005) Anti-cytokine strategies in acute pancreatitis: Pathophysiological insights and clinical implications. Rocz. Akad. Med. Białymst. 50, 106-115.

Sahu, B., Abbey, P., Anand, R., Kumar, A., Tomer, S., Malik, E. (20017) Severity assessment of acute pancreatitis using CT severity index and modified CT severity index: Correlation with clinical outcomes and severity grading as per the revised Atlanta classification. Indian J. Radiol. Imaging. 27, 152-160.

Sarr, M. G. (2013) 2012 revision of the Atlanta classification of acute pancreatitis. Pol. Arch. Med. Wewn. 123, 118-124.

Sayraç, A. V., Cete, Y., Yiğit, Ö., Aydın, A. G., Sayrac, N. (2018) Utility of HAPS for predicting prognosis in acute pancreatitis. Ulus. Travma Acil Cerrahi Derg. 24, 327-332.

Shah, A. M., Eddi, R., Kothari, S. T., Maksoud, C., DiGiacomo, W. S., Baddoura, W. (2010) Acute pancreatitis with normal serum lipase: a case series. JOP 11, 369-372.

Shah, A. S., Gupta, A. K., Ded, K. S. (2017) Assessment of PANC3 score in predicting severity of acute pancreatitis. Niger. J. Surg. 23, 53-57.

Sharma, S., Salim, M., Gothwal, S. R. (2017) A study on acute pancreatitis - Incidence, prevalence, morbidity and mortality, in Western Rajasthan. IJBAMR 6, 545-548.

Simchuk, E. J., Traverso, L. W., Nukui, Y., Kozarek, R. A. (2000) Computed tomography severity index is a predictor of outcomes for severe pancreatitis. Am. J. Surg. 179, 352-355.

Smith, R. C., Southwell-Keely, J., Chesher, D. (2005) Should serum pancreatic lipase replace serum amylase as a biomarker of acute pancreatitis? ANZ J. Surg. 75, 399-404.

Smotkin, J., Tenner, S. (2002) Clinical reviews: Pancreatic and biliary disease: Laboratory diagnostic tests in acute pancreatitis. J. Clin. Gastroenterol. 34, 459-462.

Stirling, A. D., Moran, N. R., Kelly, M. E., Ridgway, P. F., Conlon, K. C. (2017) The predictive value of C-reactive protein (CRP) in acute pancreatitis - Is interval change in CRP an additional indicator of severity? HPB (Oxford) 19, 874-880.

Swaroop, V. S., Chari, S. T., Clain, J. E. (2004) Acute severe pancreatitis. JAMA 291, 2865-2868.

Takeda, K., Yokoe, M., Takada, T., Kataoka, K., Yoshida, M., Gabata, T., Hirota, M., Mayumi, T., Kadoya, M., Yamanouchi, E., Hattori, T., Sekimoto, M., Amano, H., Wada, K., Kimura, Y., Kiriyama, S., Arata, S., Takeyama, Y., Hirota, M., Hirata, K., Shimosegawa, T. (2010) Assessment of severity of acute pancreatitis according to new prognostic factors and CT grading. J. Hepatobiliary Pancreat. Sci. 17, 37-44.

Talukdar, R., Bhattacharrya, A., Rao, B., Sharma, M., Reddy, D. N. (2014a) Clinical utility of the revised Atlanta classification of acute pancreatitis in a prospective cohort: have all loose ends been tied? Pancreatology 14, 257-262.

Talukdar, R., Sharma, M., Deka, A., Teslima, S. (2014b) Utility of the "harmless acute pancreatitis score" in predicting a non-severe course of acute pancreatitis: a pilot study in an Indian cohort. Indian J. Gastroenterol. 33, 316-321. 
Tandon, R. K. (2013) Management of acute pancreatitis: Indian guidelines and protocols. API Med. Update 23, 267-270.

Tang, W., Zhang, X. M., Xiao, B., Zeng, N. L., Pan, H. S., Feng, Z. S., Xu, X. X. (2011) Magnetic resonance imaging versus Acute Physiology and Chronic Healthy Evaluation II score in predicting the severity of acute pancreatitis. Eur. J. Radiol. 80, 637-642.

Taylor, S. L., Morgan, D. L., Denson, K. D., Lane, M. M., Pennington, L. R. (2005) A comparison of the Ranson, Glasgow, and APACHE II scoring systems to a multiple organ system score in predicting patient outcome in pancreatitis. Am. J. Surg. 189, 219-222.

Telem, D. A., Bowman, K., Hwang, J., Chin, E. H., Nguyen, S. Q., Divino, C. M. (2009) Selective management of patients with acute biliary pancreatitis. J. Gastrointest. Surg. 13, 2183-2188.

Tenner, S., Dubner, H., Steinberg, W. (1994) Predicting gallstone pancreatitis with laboratory parameters: a meta-analysis. Am. J. Gastroenterol. 89, 1863-1866.

Tenner, S., Baillie, J., DeWitt, J., Vege, S. S.; American College of Gastroenterology (2013) American College of Gastroenterology guideline: management of acute pancreatitis. Am. J. Gastroenterol. 108, 1400-1415.

Thoeni, R. F. (2012) The revised Atlanta classification of acute pancreatitis: Its importance for the radiologist and its effect on treatment. Radiology 262, 751-764.

Thomson, H. J. (1985) Acute pancreatitis in north and north-east Scotland. J. R. Coll. Surg. Edinb. 30, $104-111$.

Toouli, M., Brooke-Smith, C., Bassi, D., Carr-Locke, J., Telford, P., Freeny, C., Imrie, R., Tandon; Working Party of the Program Committee of the Bangkok World Congress of Gastroenterology (2002) Guidelines for the management of acute pancreatitis. J. Gastroenterol. Hepatol. 17, S15-S39.

Triester, S. L., Kowdley, K. V. (2002) Prognostic factors in acute pancreatitis. J. Clin. Gastroenterol. 34, $167-176$. Ueda, T., Takeyama, Y., Yasuda, T., Kamei, K., Satoi, S., Sawa, H., Shinzeki, M., Ku, Y., Kuroda, Y., Ohyanagi, H. (2009) Utility of the new Japanese severity score and indications for special therapies in acute pancreatitis. J. Gastroenterol. 44, 453-459.

Van Santvoort, H. C., Bakker, O. J., Bollen, T. L., Bollen, T. L., Besselink, M. G., Ali, U. A., Schrijver, A. M., Boermeester, M. A., van Goor, H., Dejong, C. H., van Eijck, C. H., van-Ramshorst, B., Schaapherder, A. F., van der Harst, E., Hofker, S., Nieuwenhuijs, V. B., Brink, M. A., Kruyt, P. M., Manusama, E. R., van-der-Schelling, G. P., Karsten, T., Hesselink, E. J., van-Laarhoven, C. J., Rosman, C., Bosscha, K., deWit, R. J., Houdijk, A. P., Cuesta, M. A., Wahab, P. J., Gooszen, H. G.; Dutch Pancreatitis Study Group (2011) A conservative and minimally invasive approach to necrotizing pancreatitis improves outcome. Gastroenterology 141, 1254-1263.

Vege, S. S., Gardner, T. B., Chari, S. T., Munukuti, P., Pearson, R. K., Clain, J. E., Petersen, B. T., Baron, T. H., Farnell, M. B., Sarr, M. G. (2009) Low mortality and high morbidity in severe acute pancreatitis without organ failure: A case for revising the Atlanta classification to include "moderately severe acute pancreatitis". Am. J. Gastroenterol. 104, 710-715.

Waller, A., Long, B., Koyfman, A., Gottlieb, M. (2018) Acute pancreatitis: Updates for emergency clinicians. J. Emerg. Med. 55, 769-779.

Wereszczynska, S., Dabrowski, A., Jedynak, M., Gabryelewicz, A. (1998) Oxidative stress as an early prognostic factor in acute pancreatitis (AP): Its correlation with serum phospholipase A2 (PLA2) and plasma polymorphonuclear elastase (PMN-E) in different-severity forms of human AP. Pancreas 17, 163-168.

Whitcomb, D. C. (2006) Acute pancreatitis. N. Engl. J. Med. 354, 2142-2150.

Wilcox, C. M., Kilgore, M. (2009) Cost minimization analysis comparing diagnostic strategies in unexplained pancreatitis. Pancreas 38, 117-121.

Working Group IAPAPAAPG (2013) IAP/APA evidence-based guidelines for the management of acute pancreatitis. Pancreatology 13, e1-15. 
86) Prague Medical Report / Vol. 121 (2020) No. 2, p. 65-86

Working Party of the British Society of Gastroenterology, Association of Surgeons of Great Britain and Ireland, Pancreatic Society of Great Britain and Ireland, Association of Upper GI Surgeons of Great Britain and Ireland (2005) UK guidelines for the management of acute pancreatitis. Gut 54, iii1-iii9 (Suppl. 3).

Wu, B. U., Johannes, R. S., Sun, X., Tabak, Y., Conwell, D. L., Banks, P. A. (2008) The early prediction of mortality in acute pancreatitis: a large population-based study. Gut. 57, 1698-1703.

Wu, B. U., Bakker, O. J., Papachristou, G. I., Besselink, M. G., Repas, K., van-Santvoort, H. C., Muddana, V., Singh, V. K., Whitcomb, D. C., Gooszen, H. G., Banks, P. A. (2011) Blood urea nitrogen in the early assessment of acute pancreatitis: an international validation study. Arch. Intern. Med. 171, 669-676.

Yadav, D., Agarwal, N., Pitchumoni, C. S. (2002) A critical evaluation of laboratory tests in acute pancreatitis. Am. J. Gastroenterol. 97, 1309-1318.

Yokoe, M., Takada, T., Mayumi, T., Yoshida, M., Isaji, S., Wada, K., Itoi, T., Sata, N., Gabata, T., Igarashi, H., Kataoka, K., Hirota, M., Kadoya, M., Kitamura, N., Kimura, Y., Kiriyama, S., Shirai, K., Hattori, T., Takeda, K., Takeyama, Y., Hirota, M., Sekimoto, M., Shikat, S., Arata, S., Hirata, K. (2015) Japanese guidelines for the management of acute pancreatitis: Japanese guidelines 2015. J. Hepatobiliary Pancreat. Sci. 22, 405-432.

Zhao, K., Adam, S. Z., Keswani, R. N., Horowitz, J. M., Miller, F. H. (2015) Acute pancreatitis: Revised Atlanta classification and the role of cross-sectional imaging. AJR Am. J. Roentgenol. 205, W32-W41. 